\title{
Three weekly versus weekly concurrent cisplatin: safety propensity score analysis on 166 head and neck cancer patients
}

\author{
Michela Buglione ${ }^{1 \dagger}$, Daniela Alterio ${ }^{2 \dagger}$, Marta Maddalo ${ }^{1}$, Diana Greco ${ }^{1}$, Marianna Alessandra Gerardi ${ }^{2 *} \mathbb{0}$, \\ Davide Tomasini ${ }^{1}$, Ludovica Pegurri ${ }^{1}$, Matteo Augugliaro' ${ }^{2}$ Giulia Marvaso ${ }^{2,3}$, Irene Turturici ${ }^{2}$, Andrea Guerini ${ }^{1}$, \\ Mohssen Ansarin ${ }^{4}$, Luigi Spiazzi ${ }^{5}$, Loredana Costa ${ }^{1}$, Maria Cossu Rocca ${ }^{6}$, Stefano Maria Magrini ${ }^{1 \dagger}$ and \\ Barbara Alicja Jereczek-Fossa ${ }^{2,3+}$
}

\begin{abstract}
Background: Radio-chemotherapy with CDDP is the standard for H\&N squamous cell cancer. CDDP $100 \mathrm{mg} / \mathrm{m}^{2} / \mathrm{q}^{3}$ is the standard; alternative schedules are used to reduce toxicity, mostly $40 \mathrm{mg} / \mathrm{m}^{2} / \mathrm{q} 1$.

Methods: Patients were treated from 1/2010 to 1/2017 in two Radiation Oncology Centres. Propensity score analysis (PS) was retrospectively used to compare these two schedules.

Results: Patients analyzed were 166. Most (114/166) had 1w-CDDP while 52 had 3w-CDDP. In the 3w-CDDP group, patients were younger, with better performance status, smaller disease extent and a more common nodal involvement than in the $1 \mathrm{w}$-CDDP. Acute toxicity was similar in the groups. Treatment compliance was lower in the w-CCDP. Overall survival before PS was better for female, for oropharyngeal disease and for $3 \mathrm{w}$-CDDP group. After PS, survival was not related to the CDDP schedule.
\end{abstract}

Conclusions: $3 w$-CDDP remains the standard for fit patients, weekly schedule could be safely used in selected patients.

Keywords: H\&N cancer, Radiotherapy, Chemotherapy, Weekly-CDDP, 3weekly-CDDP

\section{Introduction}

For decades, CDDP has been used in the management of locally advanced squamous cell carcinoma of the head and neck (LAHNSCC) in order to enhance the tumoricidal activity of radiation. Among the various CDDP schedules proposed, differing in frequency, dose, and administration, there is level 1 evidence for improvement

\footnotetext{
*Correspondence: marianna.gerardi@ieo.it

${ }^{\dagger}$ Michela Buglione and Daniela Alterio are co-first authors; Stefano Maria

Magrini and Barbara Alicja Jereczek-Fossa are co-last authors

${ }^{2}$ Division of Radiotherapy, Radiation Oncology Department, IEO

European Institute of Oncology, IRCCS, Via Ripamonti 435, 20141 Milan, Italy

Full list of author information is available at the end of the article
}

in loco-regional control and/or overall survival, achieved by three-weekly high-dose $\left(100 \mathrm{mg} / \mathrm{m}^{2}\right)$ cisplatin concurrently with conventional external beam radiotherapy, when compared with radiotherapy alone. The supporting data originate from four large randomized phase III trials investigating the role of cisplatin in both the definitive and postoperative settings [1-4].

Since three-weekly cisplatin ( $3 \mathrm{w}-\mathrm{CDDP})$ causes significant acute toxicity in more than three quarters of patients, many patients are likely to receive sub-optimal cumulative cisplatin dose and dose intensity. This could hamper treatment outcomes and require a proper patient's selection.

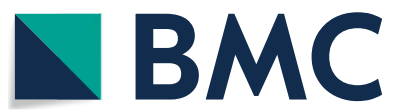

(c) The Author(s) 2021. Open Access This article is licensed under a Creative Commons Attribution 4.0 International License, which permits use, sharing, adaptation, distribution and reproduction in any medium or format, as long as you give appropriate credit to the original author(s) and the source, provide a link to the Creative Commons licence, and indicate if changes were made. The images or other third party material in this article are included in the article's Creative Commons licence, unless indicated otherwise in a credit line to the material. If material is not included in the article's Creative Commons licence and your intended use is not permitted by statutory regulation or exceeds the permitted use, you will need to obtain permission directly from the copyright holder. To view a copy of this licence, visit http://creativecommons.org/licenses/by/4.0/. The Creative Commons Public Domain Dedication waiver (http://creativeco mmons.org/publicdomain/zero/1.0/) applies to the data made available in this article, unless otherwise stated in a credit line to the data. 
Low-dose weekly cisplatin (1w-CDDP) regimes have gained large clinical acceptance, replacing the standard $3 \mathrm{w}$-CDDP schedule at many institutions in daily clinical practice. The background of this choice is the assumption that low-dose, $1 \mathrm{w}$-CDDP could increases treatment compliance maintaining dose intensity and avoiding interruptions of radiotherapy [5]. It could also reduce chemotherapy-related acute and late side effects, facilitate dose adjustments according to clinical conditions during the treatment and therefore outpatient management, with lower hospitalization rates. Several retrospective and prospective studies [6-9], as well as different systematic reviews and meta-analysis [10-13] comparing $1 \mathrm{w}$ - and $3 \mathrm{w}$ - schedules, showed conflicting and inconclusive results, both in terms of survival outcomes and toxicity profile. Indeed, while most of these studies confirmed that oncologic outcome seems to be similar between the two regimens, hematologic toxicity showed not homogeneous findings among the different analyzed cohort.

Different prospective randomized trial are actually ongoing in curative setting of both LAHNSCC and nasopharyngeal cancer (NCT03998696, NCT03649048, NCT01171781, JPRN-jRCTs031180135, NCT03998696, NCT03649048). Weekly 1w-schedules have also been included in de-intensification trials for human papilloma virus-related tumors (NCT01530997, NCT01687413).

Therefore, waiting for definitive results, there is an unmet need to provide literature data on homogenous cohorts of patients treated with $1 \mathrm{w}$-CDDP to guide the daily clinical practice.

In this contest, the main objective of this retrospective analysis is to compare, in a real-life setting of patients treated with definitive chemo-radiotherapy, two chemotherapy schedules $\left(1 \mathrm{w}-\mathrm{CDDP} 40 \mathrm{mg} / \mathrm{m}^{2}\right.$ vs $3 \mathrm{w}-\mathrm{CDDP}$ $100 \mathrm{mg} / \mathrm{m}^{2}$ ) concomitant to radical radiotherapy in locally advanced head and neck cancers, in terms of acute and overall and relapse free survival. The Propensity Score matched analysis should help to reduce the selection biases that are usually present in a retrospective series.

\section{Materials and methods}

Patients enrolled in this retrospective analysis have been treated between January 1st, 2010 and January 30th, 2017 for LAHNSCC (oropharynx, hypopharynx and larynx) at the Radiation Oncology Departments of the Brescia University ("O. Alberti", ASST-Spedali Civili-IRA) and of the European Institute of Oncology (IEO IRCCS)/University of Milan, Italy.

All patients had concomitant CDDP-based definitive chemo-radiotherapy. Two different CDDP schedules were used in the two Institutions: $100 \mathrm{mg} / \mathrm{m}^{2}$ every three weeks (3w-CDDP, IEO) and weekly $40 \mathrm{mg} /$ $\mathrm{m}^{2}$ (1w-CDDP, IRA). Patients treated with adjuvant chemo-radiotherapy were not included in the analysis. In order to reduce the variability related to the patient's body surface differences, the dose was considered as dose $/ \mathrm{m}^{2}$ (ratio of total CDDP dose received by each patient and his/her body surface).

Data were retrospectively collected using a database where all the clinical and therapeutic features were entered.

The ethical committee of the two Institutions approved/notified the study.

Stage classification was carried out in accordance with the TNM classification system, VII Ed. [14].

Acute radiation and chemotherapy-related toxicities were analyzed weekly and registered as the higher score occurred during and 3 months after radiotherapy, according to the Common Toxicity Criteria for Adverse Effects (CTCAE) v.4.03.

The RT completion date was chosen as reference for measuring survival data. Relapse Free Survival (RFS) was measured as months free from local/distant relapse after the end of radio-chemotherapy; Overall Survival (OS) was the time from the end of radio-chemotherapy to death for any cause or last follow up, for living patients.

\section{Statistical analysis}

The differences between the two treatments were investigated through the $\chi^{2}$ test.

OS and RFS were calculated through the KaplanMeier method and the differences evaluated with the Log-Rank Test.

The Propensity Score matched analysis (PS) (OS and RFS) was introduced to minimize the effect of confounding factors and to create two homogeneous populations ( $\mathrm{w}$-CDDP vs $3 \mathrm{w}$-CDDP). The variables to match the patients (2:1) were age, disease stage and performance status (Karnofsky Performance Status, KPS). At the end, 160 patients were evaluable after the match (114 and 46 patients respectively in the $1 \mathrm{w}$ and $3 \mathrm{w}$-CDDp group).

The multivariate analysis was done (OS and RFS) with Cox Regression model, both before and after PS, including all the variables used in the univariate one.

After PS the univariate and multivariate analysis were applied on the group of patients with oropharynx disease (113 patients). A separate analysis "HPV-status"related, was not performed for the exiguity of the analysis.

The statistical analysis was made using the $\mathrm{IBM}^{\circledR}$ SPSS Statistics ${ }^{\circledR} \mathrm{v} 25.0$; the $p$ values were considered significant when $p \leq 0.05$. 


\section{Results}

One hundred sixty-six patients were included in the analysis. Seventy-five percent $(n=125)$ were male, 140 (84\%) aged $<70$ years, 109 in good general conditions $(\mathrm{KPS}=90-100,66 \%)$. Almost 50\% $(\mathrm{n}=84)$ were tobacco smokers and had a current use of alcohol $(\mathrm{n}=90)$. The patient's features for the series are shown in Table 1.

The distribution of the clinical characteristics was not homogeneous in the two groups (Table 1). Patients treated with $1 \mathrm{w}$-CDDP were significantly older $(p=0.005)$, in worse general conditions $(p=0.000)$ and more frequently actual smokers and alcohol consumers $(p=0.000)$.

Primary disease site was oropharynx in 119 patients (71.7\%). In 129 cases, the disease was in stage IV (77.7\%). Human Papilloma Virus status (HPV) was determined in $36.14 \%$ (60) of cases (Table 2).

The two treatment groups appear to be non-homogeneous, with a statistically significant prevalence of oropharyngeal tumors $(90 \%$ vs $65 \%, p=0.001)$ and $\mathrm{N} 2-3$ disease $(84.7 \%$ vs $71 \%, p=0.02)$ in $3 \mathrm{w}-\mathrm{CDDP}$ group, and an excess of T3-4 disease $(54 \%$ vs $38 \% ; p=0.05)$ among w-CDDP patients. A higher rate of HPV determination and positivity is also evident in $3 \mathrm{w}-\mathrm{CDDP}$ group $(p=0.000)$ (Table 2$)$.
One hundred fourteen patients were treated with $\mathrm{w}$-CDDP $\left(40 \mathrm{mg} / \mathrm{m}^{2}\right)$ and 52 with $3 \mathrm{w}-\mathrm{CDDP}(100 \mathrm{mg} /$ $\mathrm{m}^{2}$ ). The CDDP $/ \mathrm{m}^{2}$ doses was $200-250 \mathrm{mg}$ in $25.4 \%$ in $\mathrm{w}-\mathrm{CDDP}$ and $23.1 \%$ in $3 \mathrm{w}-\mathrm{CDDP}$; $>250 \mathrm{mg} / \mathrm{m}^{2}$ in $2.6 \%$ and $50 \%$ respectively in $\mathrm{w}$ - and $3 \mathrm{w}-\mathrm{CDDP}(p=0.000)$. No patients had neo-adjuvant chemotherapy. CDDP was interrupted in $49.5 \%$ patients: $56.1 \%$ and $34.6 \%$ in $w$ and $3 \mathrm{w}$ groups respectively $(p=0.012)$. CDDP was mostly interrupted in patients treated with dose/fraction $>2$ Gy $(59.6 \%$ vs $44 \% ; p=0.052)$ and in the $w$-CDDP.

All patients were treated with radical radiotherapy using different fractionations in relation to the clinical institutional use, assuming the same biological curative effect in combination with chemotherapy [15]: 10 (6\%) patients had 69 Gy in 30 fractions (dose/fraction, $2.3 \mathrm{~Gy} / \mathrm{die}$ ); the others had 70 Gy in $2 \mathrm{~Gy} / \mathrm{fr}$ (109 pts$66 \%$ ) or 69.3 Gy with a slightly higher daily fractionation 2.1-2.12 Gy/fr (47 pts-28\%). Dose/fraction $>2$ Gy was mostly used in the weekly-CDDP group. Almost all patients had IMRT (Table 3).

Two sub-analysis were conducted on groups of patients with homogeneous KPS. In the group with KPS $<90$ $(n=57)$ no differences are evident between patients submitted to different chemotherapy schedules (age, smoking habits, site of disease). No differences are evident even in terms of interruption or dose of CDDP $/ \mathrm{m}^{2}$.

Table 1 Patients features in relation with chemotherapy schedule

\begin{tabular}{|c|c|c|c|c|}
\hline Characteristics of patients & $1 \mathrm{w}-\mathrm{CDDP}(\mathrm{N}=114)$ & $3 w \operatorname{CDDP}(\mathrm{N}=52)$ & $x^{2}$ & Entire series $\mathrm{N}(\%)$ \\
\hline \multicolumn{5}{|l|}{ Gender } \\
\hline Male & $92(80.7 \%)$ & $33(63.5 \%)$ & 0.0017 & $125(75.3 \%)$ \\
\hline Female & $22(19.3 \%)$ & $19(36.5 \%)$ & & $41(24.7 \%)$ \\
\hline \multicolumn{5}{|l|}{ Age } \\
\hline$<70$ years & 90 (78.9\%) & $50(96.2 \%)$ & 0.005 & $140(84.3 \%)$ \\
\hline$>70$ years & $24(21.1 \%)$ & $2(3.8 \%)$ & & $26(15.7 \%)$ \\
\hline \multicolumn{5}{|l|}{ Baseline KPS } \\
\hline $90-100$ & $60(52.6 \%)$ & $49(94.2 \%)$ & 0.000 & $109(65.7 \%)$ \\
\hline $70-80$ & $52(45.6 \%)$ & $3(5.8 \%)$ & & $55(33.1 \%)$ \\
\hline 60 & $2(1.8 \%)$ & $0(0 \%)$ & & $2(1.2 \%)$ \\
\hline \multicolumn{5}{|l|}{ Tobacco use } \\
\hline Currently $<10$ cigarettes/die & $14(12.3 \%)$ & $4(7.7 \%)$ & 0.000 & $18(10.8 \%)$ \\
\hline Currently 10-20 cigarettes/die & $27(23.7 \%)$ & $5(9.6 \%)$ & & $32(19.3 \%)$ \\
\hline Currently $>20$ cigarettes/die & $31(27.2 \%)$ & $3(5.8 \%)$ & & $34(20.5 \%)$ \\
\hline Stopped smoking $>5$ years & $22(19.3 \%)$ & $10(19.2 \%)$ & & $32(20.5 \%)$ \\
\hline Never smoking & $20(17.5 \%)$ & $30(57.7 \%)$ & & $50(30.1 \%)$ \\
\hline \multicolumn{5}{|l|}{ Alcohol } \\
\hline Currently & $75(65.8 \%)$ & $15(28.8 \%)$ & 0.000 & $90(54.2 \%)$ \\
\hline Past & $17(14.9 \%)$ & $1(1.9 \%)$ & & 18 (10.8\%) \\
\hline Never & $22(19.3 \%)$ & $29(55.8 \%)$ & & 51 (30.7\%) \\
\hline ND & $0(0 \%)$ & $7(13.5 \%)$ & & 7 (4.2\%) \\
\hline
\end{tabular}

$1 w$-CDDP weekly Cisplatin, 3w-CDDP three-weekly Cisplatin, KPS karnofsky performance status, ND not declared 
Table 2 Disease characteristics in relation with chemotherapy schedule in relation to chemotherapy schedule

\begin{tabular}{|c|c|c|c|c|}
\hline Disease characteristic & 1w-CDDP (N.114) & $3 w-C D D P(N .52)$ & $p$ & Entire series (\%) \\
\hline Histology & & & 0.125 & \\
\hline Squamous & $109(95.6 \%)$ & $52(100 \%)$ & & $161(97 \%)$ \\
\hline Other histology & $5(4.4 \%)$ & $0(0 \%)$ & & $5(3 \%)$ \\
\hline Site of the disease & & & 0.001 & \\
\hline Oropharynx & $72(63.2 \%)$ & $47(90.4 \%)$ & & $119(71.7 \%)$ \\
\hline Hypopharynx & $23(20.2 \%)$ & $2(3.8 \%)$ & & $25(25.1 \%)$ \\
\hline Larynx & $19(16.7 \%)$ & $3(5.8 \%)$ & & $22(13.3 \%)$ \\
\hline Staging $T$ (TNM 7th Ed) & & & 0.057 & \\
\hline $\mathrm{T} 1-\mathrm{T} 2$ & $52(45.6 \%)$ & $32(61.3 \%)$ & & $84(50.6 \%)$ \\
\hline T3-T4 & $62(54.4 \%)$ & $20(38.5 \%)$ & & $82(49.4 \%)$ \\
\hline Staging N (TNM 7th Ed) & & & 0.024 & \\
\hline No & $16(14 \%)$ & $2(3.8 \%)$ & & $18(10.8 \%)$ \\
\hline N1 & $17(14.9 \%)$ & $6(11.5 \%)$ & & $23(13.9 \%)$ \\
\hline $\mathrm{N} 2$ & $80(70.2 \%)$ & $40(76.9 \%)$ & & $120(72.3 \%)$ \\
\hline N3 & $1(0.9 \%)$ & $4(7.7 \%)$ & & $5(3 \%)$ \\
\hline Stage (AJCC 7th Ed) & & & 0.009 & \\
\hline$\|$ & $5(4.4 \%)$ & $1(1.9 \%)$ & & $6(3.6 \%)$ \\
\hline III & $28(24.6 \%)$ & $3(5.8 \%)$ & & $31(18.7 \%)$ \\
\hline IV & $81(71.1 \%)$ & $48(92.3 \%)$ & & $129(77.7 \%)$ \\
\hline HPV & & & 0.000 & \\
\hline Positive & $12(10.5 \%)$ & $32(61.5 \%)$ & & $44(26.5 \%)$ \\
\hline Negative & $11(9.6 \%)$ & $5(9.6 \%)$ & & $16(9.6 \%)$ \\
\hline ND & 91 (79.8\%) & 15 (28.8\%) & & 106 (63.9\%) \\
\hline
\end{tabular}

HPV human papilloma virus, TNM tumor, node, metastases, AJCC American Joint Committee on Cancer, $1 w$-CDDP weekly Cisplatin, $3 w$-CDDP three-weekly Cisplatin

On the other hand, in the group with KPS 90-100 $(n=109)$, the patients treated with different schedules are homogeneous only for age. A higher percentage of nonsmokers $(61.2 \%$ vs $16.7 \% ; p=0.000)$ and lower of alcohol users $(28.6 \%$ vs $58.3 \%$; $p=0.000)$ were treated with the $3 \mathrm{w}$-CDDP schedule. Less patients treated with the 3 -weekly schedule of this subgroup, interrupted chemotherapy ( $32 \%$ vs $50 \% ; p=0.081)$ and received $<200 \mathrm{mg} /$ $\mathrm{m}^{2}$ of CDDP $(24.5 \%$ vs $63.3 \% ; p=0.000)$.

\section{Acute toxicity}

The rate of G3-4 acute hematological toxicity was $19.9 \%$ in the whole group (18.4\% and $23.1 \%$ in $1 \mathrm{w}$-CDDP and $3 \mathrm{w}$-CDDP respectively $(p=\mathrm{ns})$. G1-2 anemia and leucopenia were similar in the two groups; G1-2 thrombocytopenia was slightly more frequent in patients treated with w-CDDP $(p=0.01)$ (Table 4). Overall G3-4 mucositis, dermatitis and dysphagia rate were $33 \%, 10.8 \%$ and $19 \%$ respectively. G 3-4 emesis was higher in the group treated with w-CDDP $(p=0.007)$ while G1-2 acute xerostomia was more frequent in the group treated with $3 \mathrm{w}$-CDDP $(p=0.009)$. No severe renal toxicity was recorded (Table 4).
The rate of CDDP interruption was slightly higher $(p=0.052)$ in patients treated with higher fractional dose ( $44 \%$ and $56 \%$ in the $2 \mathrm{~Gy} / \mathrm{fr}$ and $>2 \mathrm{~Gy} / \mathrm{fr}$, respectively); the same was true for cutaneous toxicity $(8.3 \%$ and $15.8 \%$, in the 2 Gyfr and $>2 \mathrm{~Gy} / \mathrm{fr}$, respectively). Patients with CDDP interruption had mostly G3-G4 vs G1-2 hematological toxicity $(66.7 \%$ vs $33.3 \% p=0.81)$.

\section{Overall survival}

Univariate analysis before and after propensity score matched analysis

After a median follow-up of 32 months (respectively 35 and $26.5 \mathrm{~m}$ for the $1 \mathrm{w}$ and $3 \mathrm{w}-\mathrm{CDDP})$, the 1,2 and 5 years actuarial OS of the entire series were $97 \%$, $88 \%$ and $81.5 \%$. Median OS was not reached neither in entire series nor in the two groups separately (1w and $3 \mathrm{w}$-CDDP).

Before Propensity scored analysis, only female patients showed a statistically significant better OS compared with male patients (Table 5). OS was significantly better in patients with oropharyngeal disease as opposed with hypo-pharyngeal/laryngeal disease $(p=0.04)$ : 1-year survival rates were $99.1 \%, 88 \%, 95.5 \%$, and 2 -and 5 -year rates of $92.3 \%, 75.1 \%, 70.6 \%$ and of $89 \%, 59.1 \%, 73.3 \%$ for 
Table 3 Treatment in relation to chemotherapy schedule

\begin{tabular}{|c|c|c|c|c|}
\hline Treatment characteristic & 1w-CDDP (N.114) & $3 w-C D D P(N .52)$ & $p$ & Entire series (\%) \\
\hline Cumulative CDDP $/ \mathrm{m}^{2}$ dose & & & 0.000 & \\
\hline$\leq 200 \mathrm{mg} / \mathrm{m}^{2}$ & $82(71.9 \%)$ & $14(26.9 \%)$ & & $96(57.8 \%)$ \\
\hline $200-250 \mathrm{mg} / \mathrm{m}^{2}$ & $29(25.4 \%)$ & $12(23.1 \%)$ & & $41(24.7 \%)$ \\
\hline$>250 \mathrm{mg} / \mathrm{m}^{2}$ & $3(2.6 \%)$ & $26(50 \%)$ & & $29(17.5 \%)$ \\
\hline Median CDDP $/ \mathrm{m}^{2}$ & $175.9 \mathrm{mg} / \mathrm{m}^{2}$ & $248.1 \mathrm{mg} / \mathrm{m}^{2}$ & 0.026 & \\
\hline \multicolumn{5}{|l|}{ CDDP interruption } \\
\hline Yes & $64(56.1 \%)$ & $18(34.6 \%)$ & 0.012 & $82(49.4 \%)$ \\
\hline No & $50(43.9 \%)$ & $34(65.4 \%)$ & & $84(50.6 \%)$ \\
\hline RTT dose & & & 0.000 & \\
\hline 69 Gy & $10(8.8 \%)$ & 0 & & $10(6 \%)$ \\
\hline$>69$ Gy and < 70 Gy & $47(41.2 \%)$ & 0 & & $47(28 \%)$ \\
\hline 70 Gy & $57(50 \%)$ & $52(100 \%)$ & & $109(66 \%)$ \\
\hline RTT dose/fraction & & & 0.000 & \\
\hline $2.3 \mathrm{~Gy} / \mathrm{fr}$ & $10(8.8 \%)$ & 0 & & $10(6 \%)$ \\
\hline $2.1-2.2 \mathrm{~Gy} / \mathrm{fr}$ & $47(41.2 \%)$ & 0 & & $47(28 \%)$ \\
\hline $2 \mathrm{~Gy} / \mathrm{fr}$ & $57(50 \%)$ & $52(100 \%)$ & & 109 (66\%) \\
\hline RTT technique & & & 0.000 & \\
\hline $3 \mathrm{D}$ & $3(2.6 \%)$ & $4(7.7 \%)$ & & $7(4.2 \%)$ \\
\hline IMRT (VMAT) & $53(46.5 \%)$ & $48(92.3 \%)$ & & $101(60.8 \%)$ \\
\hline Helical IMRT & $58(50.9 \%)$ & $0(0 \%)$ & & $58(34.9 \%)$ \\
\hline
\end{tabular}

$1 w$-CDDP weekly Cisplatin, 3w-CDDP three-weekly Cisplatin, RTT radiotherapy, IMRT intensity modulated radiation therapy, VMAT volumetric modulated arch therapy, fr fraction

oropharyngeal, hypo-pharyngeal and laryngeal cancers, respectively.

OS is different in relation with 3 months nodal response: complete response, partial response and nodal progression are respectively linked with 1 - and 2-year OS of $99 \%, 97 \%, 83 \%$ and $92 \%, 83 \%, 67 \%$, respectively $(p=0.04)$.

Univariate analysis showed that OS was inferior with $1 \mathrm{w}$-CDDP $(p=0.026) ; 12,24$ - and 60-months survival rates were $96.4 \%$ versus $98 \%, 84.6 \%$ vs 95.4 and $75.9 \%$ versus 95.4 , respectively in the $1 \mathrm{w}-\mathrm{CDDP}$ versus $3 \mathrm{w}$-CDDP. The different doses $\left(\mathrm{CDDP} / \mathrm{m}^{2}\right)$ did not impact significantly survival rates neither if used as categorical or continuous variables. Survival was better, without statistically significance, for patients who did not interrupt chemotherapy. The other clinical and therapeutic variables did not show statistically differences (Table 5 ).

After propensity score matched analysis the statistically significant better OS in female patients $(p=0.041)$ and in oropharyngeal disease $(p=0.047)$ was confirmed. The worse prognosis of patients with more extensive nodal involvement (N3, $p=0.011$ ) was also demonstrated. Better OS for patients treated with $3 \mathrm{w}-\mathrm{CDDP}$ was not confirmed (Table 5).

In the group of patients with oropharyngeal disease, at univariate analysis after PS, the variable significantly influencing overall survival was total CDDP dose $(p=0.016)$ (Fig. 1).

\section{Multivariate analysis before and after propensity score matched analysis}

The multivariate analysis before the propensity score analysis showed better survival in patients with oropharyngeal cancer, treated with $3 \mathrm{w}-\mathrm{CDDP}$ and with higher total $\mathrm{CDDP} / \mathrm{m}^{2}$ (Table 5).

The analysis after PS demonstrated better survival in patients with oropharyngeal disease and low nodal disease burden. None of the therapeutic factors related to chemotherapy or radiotherapy, revealed impact on OS (Table 5).

Within the oropharyngeal disease group, the multivariate after PS confirmed that dose of CDDP maintained a slightly statistically significant impact on survival $(p=0.07)$ with lower death risk in patients treated with higher doses: ExpB 0.418 of 200-250 mg and 0.061 of $>250 \mathrm{mg}$ in comparison to $<200 \mathrm{mg}$ CDDP dose).

\section{Relapse free survival}

\section{Univariate analysis before and after propensity score matched analysis (PS)}

Mean relapse free survival (RFS) was 69 months (range 63-75 months). Median RFS was not reached neither before nor after the propensity scored analysis. 
Table 4 Acute toxicity as registered during the treatment

\begin{tabular}{|c|c|c|c|c|}
\hline Acute toxicity & $1 \mathrm{~W}-\mathrm{CDDP}(\mathrm{N} .114)$ & $3 \mathrm{~W}-\mathrm{CDDP}$ (N.52) & $x^{2}$ & Entire series \\
\hline Whole hematol tox & & & 0.285 & \\
\hline Go & $9(7.9 \%)$ & $1(1.9 \%)$ & & $10(6 \%)$ \\
\hline G1-G2 & $84(73.7 \%)$ & $39(75 \%)$ & & $123(74 \%)$ \\
\hline G3-G4 & $21(18.4 \%)$ & $12(23.1 \%)$ & & $33(20 \%)$ \\
\hline Anemia & & & 0.37 & \\
\hline G0 & $11(9.6 \%)$ & $6(11.5 \%)$ & & $17(10.2 \%)$ \\
\hline G1-G2 & $102(89.5 \%)$ & $44(84.6 \%)$ & & $146(88 \%)$ \\
\hline G3-G4 & $1(0.9 \%)$ & $2(3.8 \%)$ & & $3(1.8 \%)$ \\
\hline Leucopenia & & & 0.524 & \\
\hline G0 & $16(14 \%)$ & $7(13.5 \%)$ & & $23(14 \%)$ \\
\hline G1-G2 & $80(70.2 \%)$ & $33(63.5 \%)$ & & $113(68 \%)$ \\
\hline G3-G4 & $18(15.8 \%)$ & $12(23.1 \%)$ & & $30(18 \%)$ \\
\hline Thrombocytopenia & & & 0.01 & \\
\hline Go & $26(22.8 \%)$ & $24(46.2 \%)$ & & $50(30 \%)$ \\
\hline G1-G2 & $85(74.6 \%)$ & $27(51.9 \%)$ & & $112(67.5 \%)$ \\
\hline G3-G4 & $3(2.6 \%)$ & $1(1.9 \%)$ & & $4(2.5 \%)$ \\
\hline Kidney injury & & & 0.111 & \\
\hline G0 & $89(78.1 \%)$ & $46(88.5 \%)$ & & $135(81.4 \%)$ \\
\hline G1-G2 & 25 (21.9\%) & $6(11.5 \%)$ & & $31(18.6 \%)$ \\
\hline G3-G4 & & & & \\
\hline Mucositis & & & 0.637 & \\
\hline G0 & $2(1.8 \%)$ & - & & $2(1.2 \%)$ \\
\hline $\mathrm{G} 1-\mathrm{G} 2$ & 72 (63.2\%) & $36(69.2 \%)$ & & $108(65 \%)$ \\
\hline G3-G4 & 39 (34.2\%) & $16(30.8 \%)$ & & $55(33.2 \%)$ \\
\hline ND & $1(0.9 \%)$ & - & & $1(0.6 \%)$ \\
\hline Dermatitis & & & 0.067 & \\
\hline G0 & $4(3.5 \%)$ & - & & $4(2.5 \%)$ \\
\hline G1-G2 & 88 (77.2\%) & 48 (92.3\%) & & $136(81.9 \%)$ \\
\hline G3-G4 & $14(12.6 \%)$ & $4(7.7 \%)$ & & $18(10.8 \%)$ \\
\hline ND & $8(7 \%)$ & - & & $8(4.8 \%)$ \\
\hline Xerostomia & & & 0.009 & \\
\hline G0 & 29 (25.4\%) & $9(17.3 \%)$ & & 38 (22.9\%) \\
\hline G1-G2 & 68 (59.6\%) & 43 (82.7\%) & & $111(66.9 \%)$ \\
\hline G3-G4 & $4(3.5 \%)$ & - & & $4(2.4 \%)$ \\
\hline ND & $13(11.4 \%)$ & - & & 13 (7.8\%) \\
\hline Dysphagia & & & 0.312 & \\
\hline G0 & $18(15.8 \%)$ & $5(9.6 \%)$ & & $23(13.8 \%)$ \\
\hline G1-G2 & 72 (63.2\%) & 39 (75\%) & & $111(66.9 \%)$ \\
\hline G3-G4 & $24(21.1 \%)$ & $8(15.4 \%)$ & & 32 (19.3\%) \\
\hline
\end{tabular}

$1 w$-CDDP weekly Cisplatin, $3 w$-CDDP three-weekly Cisplatin, $N d$ not declared

At univariate analysis, before PS, RFS was not related to chemotherapy ( $1 \mathrm{w}$-CDDP vs $3 \mathrm{wCDDP})(p=0.21)$ with 12 - and 24 -months survival rates of $85 \%$ versus $74 \%, 79 \%$ versus $67.5 \%$ in $1 \mathrm{w}$-CDDP versus $3 \mathrm{w}$-CDDP group, respectively. The other variables did not show statistically significant differences.
The results after the propensity score match were almost the same as those registered before applying the propensity analysis (Table 6) (Fig. 2).

The same results were confirmed, both to univariate and multivariate analysis, within the group of patients with oropharyngeal disease (data not shown). 
Table 5 One- and two year overall (OS) survival before and after the propensity score matched analysis (PS)

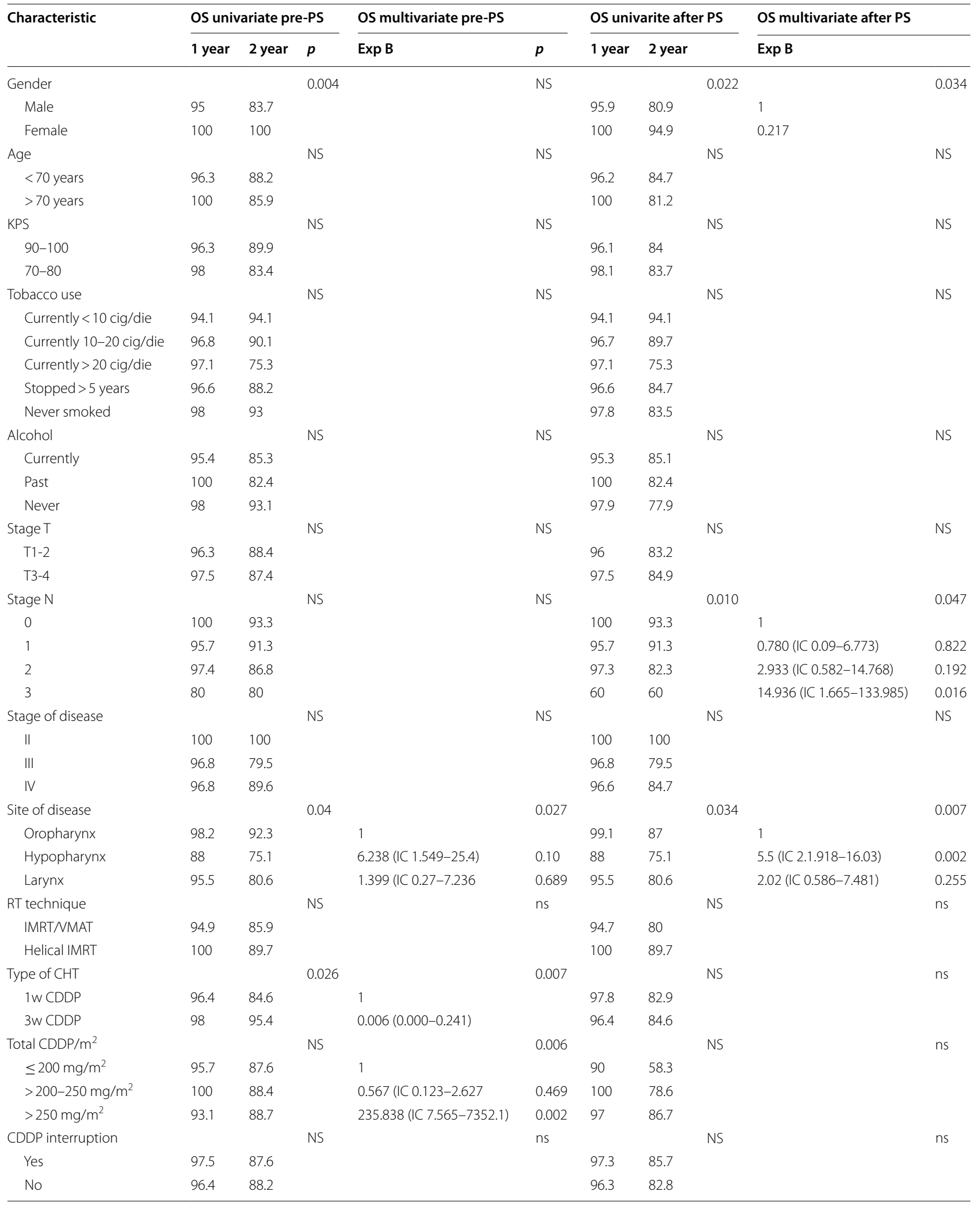


Table 5 (continued)

RTT radiotherapy, IMRT intensity modulated radiation therapy, VMAT volumetric modulated arch therapy, $1 w$-CDDP weekly Cisplatin, $3 w$-CDDP three-weekly Cisplatin, NS not significant

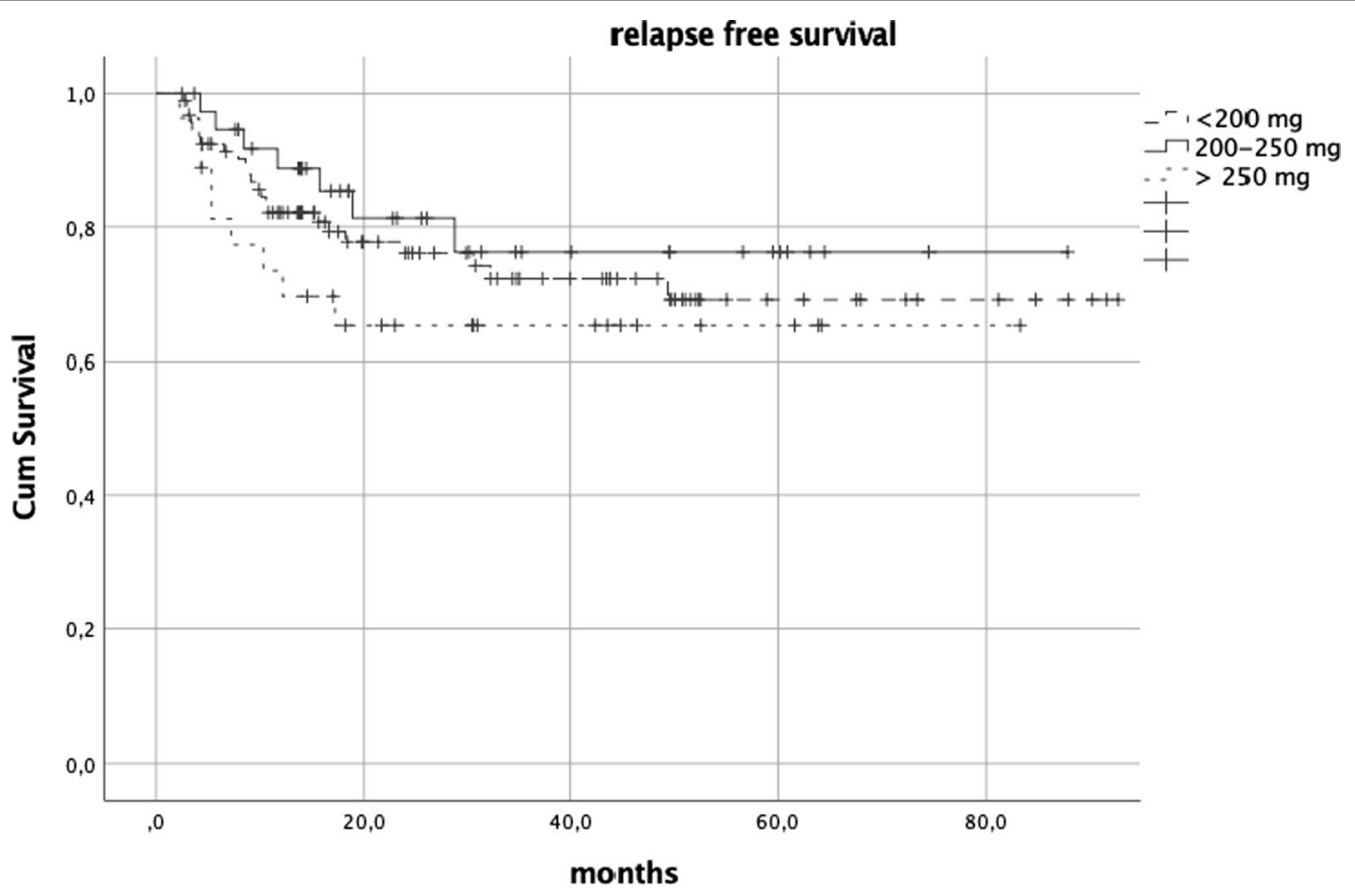

Fig. 1 OS univariate analysis after PS in patients with oropharyngeal disease $(p=0.016)$

The loco-regional ( $\mathrm{T}$ and $\mathrm{N}$ ) median free survival was not statistically different between the two groups neither before $(p=0.453)$ nor after $(p=0.394)$ propensity score analysis.

\section{Multivariate analysis after PS}

The multivariate analysis confirmed the gender as independent factor predicting RFS (Table 6).

\section{Discussion}

Due to its ability to increase the tumoricidal activity of radiotherapy, cisplatin is the standard agent, in combination with radiotherapy, to treat LAHNSCC fit patients, both with curative and postoperative intent [2, 4, 16-18].

Although several papers about the use of different CDDP schedules are present, the $3 \mathrm{w}$-CDDP regimen, supported by level 1 data, show a significant increase in overall survival and loco-regional disease control compared to radiotherapy alone [1-4, 19]. Despite benefit in terms of disease control, this chemotherapy schedule is burdened by severe toxicity, both acute and chronic, in particular myelotoxicity and mucositis [6].

Adequate pretreatment patients' characteristics remain crucial and difficult to be determined upfront. Indeed, frail patients (with older age and low performance status) could benefit from less toxic chemotherapy regimens [20-22].

Many efforts have been made to identify an alternative CDDP schedule achieving optimal disease control with minimal complications in order to reduce toxicity and, possibly, treatment interruptions that could compromise the treatment efficacy.

Different meta-analyses have been published on the topic. Jian [5] analyzed studies published from 2006 to 2014 comparing weekly Cisplatin $\left(25-40 \mathrm{mg} / \mathrm{m}^{2}\right)$ with the three-weekly one (Cisplatin at $80-100 \mathrm{mg} / \mathrm{m}^{2}$ ), in combination with radiotherapy for the treatment of stage II-IV head and neck cancers (including nasopharynx). No significant differences in 2-(Hazard Ratio-HR-1.05, $p=0.85$ ) and 3-year OS (HR 1.12, $p=0.65)$ were evident between the two schedules; also, 1- and 2-year Local Relapse Free Survival (LRFS) were similar, (HR 1.26, $p=0.65$ and 1.14, $p=0.74$ respectively). Better 5-year OS (HR 1.75, $p=0.006$ ) was registered for the $3 \mathrm{w}$-CDDP schedule. In this paper, however, it is not clearly defined if patients treated with $3 \mathrm{w}$-CDDP had a better KPS or if KPS influences the outcome. The reported better longterm survival, evaluated only on two included papers, 
Table 6 Relapse free survival before and after the propensity score matched analysis (PS)

\begin{tabular}{|c|c|c|c|c|c|c|c|c|c|c|}
\hline \multirow[t]{2}{*}{ Characteristic } & \multicolumn{3}{|c|}{ RFS univariate pre PS } & \multicolumn{2}{|c|}{$\begin{array}{l}\text { RFS multivariate } \\
\text { pre-PS }\end{array}$} & \multicolumn{3}{|c|}{ RFS univariate post PS } & \multicolumn{2}{|c|}{$\begin{array}{l}\text { RFS multivariate } \\
\text { post-PS }\end{array}$} \\
\hline & 1 year & 2 year & $p$ & Exp B & $p$ & 1 year & 2 year & $p$ & Exp-B & $p$ \\
\hline Gender & & & NS & & 0.035 & & & 0.027 & & 0.015 \\
\hline Male & 78.7 & 71 & & & & 78.7 & 71 & & 1 & \\
\hline Female & 90.2 & 86.8 & & & & 94.2 & 90.3 & & $\begin{array}{l}0.229 \text { (IC } \\
0.07-0.7488)\end{array}$ & \\
\hline Age & & & NS & & NS & & & NS & & NS \\
\hline$<70$ years & 80.6 & 75 & & & & 81.2 & 74.1 & & & \\
\hline$>70$ years & 87.7 & 82.2 & & & & 87.7 & 82.2 & & & \\
\hline KPS & & & NS & & NS & & & NS & & NS \\
\hline $90-10$ & 80.9 & 74.9 & & & & 81.7 & 75.4 & & & \\
\hline $70-80$ & 82.5 & 74.8 & & & & 82.5 & 74.8 & & & \\
\hline Tobacco use & & & NS & & NS & & & NS & & NS \\
\hline Currently < 10 cigarettes/die & 83 & 75.4 & & & & 83 & 75.4 & & & \\
\hline Currently 10-20 cigarettes/die & 87 & 77.6 & & & & 86.5 & 76.6 & & & \\
\hline Currently $>20$ cigarettes/die & 78.3 & 73.8 & & & & 78.3 & 73.7 & & & \\
\hline Stopped smoking $>5$ years & 82.5 & 78.7 & & & & 81.8 & 77.9 & & & \\
\hline Never smoked & 79.5 & 72.9 & & & & 82.3 & 74.9 & & & \\
\hline Alcohol & & & NS & & NS & & & NS & & NS \\
\hline Currently & 85.8 & 79 & & & & 85.7 & 78.7 & & & \\
\hline Past & 76.7 & 63.8 & & & & 76.7 & 63.8 & & & \\
\hline Never & 78.4 & 76.2 & & & & 78.7 & 76.3 & & & \\
\hline Stage $T$ & & & NS & & NS & & & NS & & NS \\
\hline $\mathrm{T} 1-2$ & 82.5 & 77.9 & & & & 83.6 & 78.9 & & & \\
\hline T3-4 & 80.9 & 72.1 & & & & 80.9 & 72.1 & & & \\
\hline Stage N & & & NS & & NS & & & NS & & NS \\
\hline 0 & 88.9 & 82.1 & & & & 88.9 & 82.1 & & & \\
\hline 1 & 91.1 & 85 & & & & 91.1 & 85 & & & \\
\hline 2 & 79.8 & 74.2 & & & & 80.4 & 74.5 & & & \\
\hline 3 & 53.3 & 26.7 & & & & 26.7 & 26.7 & & & \\
\hline Stage of disease & & & NS & & NS & & & NS & & NS \\
\hline$\|$ & 100 & 100 & & & & 100 & 100 & & & \\
\hline III & 83.4 & 79.5 & & & & 83.4 & 79.5 & & & \\
\hline IV & 80.4 & 72.8 & & & & 81 & 73.1 & & & \\
\hline Site of disease & & & NS & & NS & & & NS & & NS \\
\hline Oropharynx & 84.9 & 78.8 & & & & 85.9 & 79.4 & & & \\
\hline Hypopharynx & 84 & 68.5 & & & & 84 & 68.5 & & & \\
\hline Larynx & 63 & 63 & & & & 63 & 63 & & & \\
\hline RT technique & & & NS & & NS & & & NS & & NS \\
\hline IMRT/NMAT & 76.7 & 69.5 & & & & 77.5 & 70 & & & \\
\hline Helical IMRT & 92.3 & 82.6 & & & & 92.3 & 86.4 & & & \\
\hline Type of CHT & & & NS & & NS & & & NS & & NS \\
\hline $1 w-C D D P$ & 85.2 & 78.9 & & & & 75.2 & 67.6 & & & \\
\hline $3 w-C D D P$ & 74.3 & 67.5 & & & & 85.2 & 78.9 & & & \\
\hline Total CDDP/m² & & & NS & & NS & & & NS & & NS \\
\hline$<200 \mathrm{mg} / \mathrm{m}^{2}$ & 66.7 & 53.3 & & & & 48 & 48 & & & \\
\hline $200-250 \mathrm{mg} / \mathrm{m}^{2}$ & 85.9 & 85.9 & & & & 93.3 & 93.3 & & & \\
\hline$>250 \mathrm{mg} / \mathrm{m}^{2}$ & 82.3 & 75.6 & & & & 82.9 & 76 & & & \\
\hline CDDP interruption & & & NS & & NS & & & NS & & NS \\
\hline Yes & 79.6 & 76.2 & & & & 79.8 & 76.3 & & & \\
\hline No & 83.8 & 74.2 & & & & 84.7 & 74.7 & & & \\
\hline
\end{tabular}


Table 6 (continued)

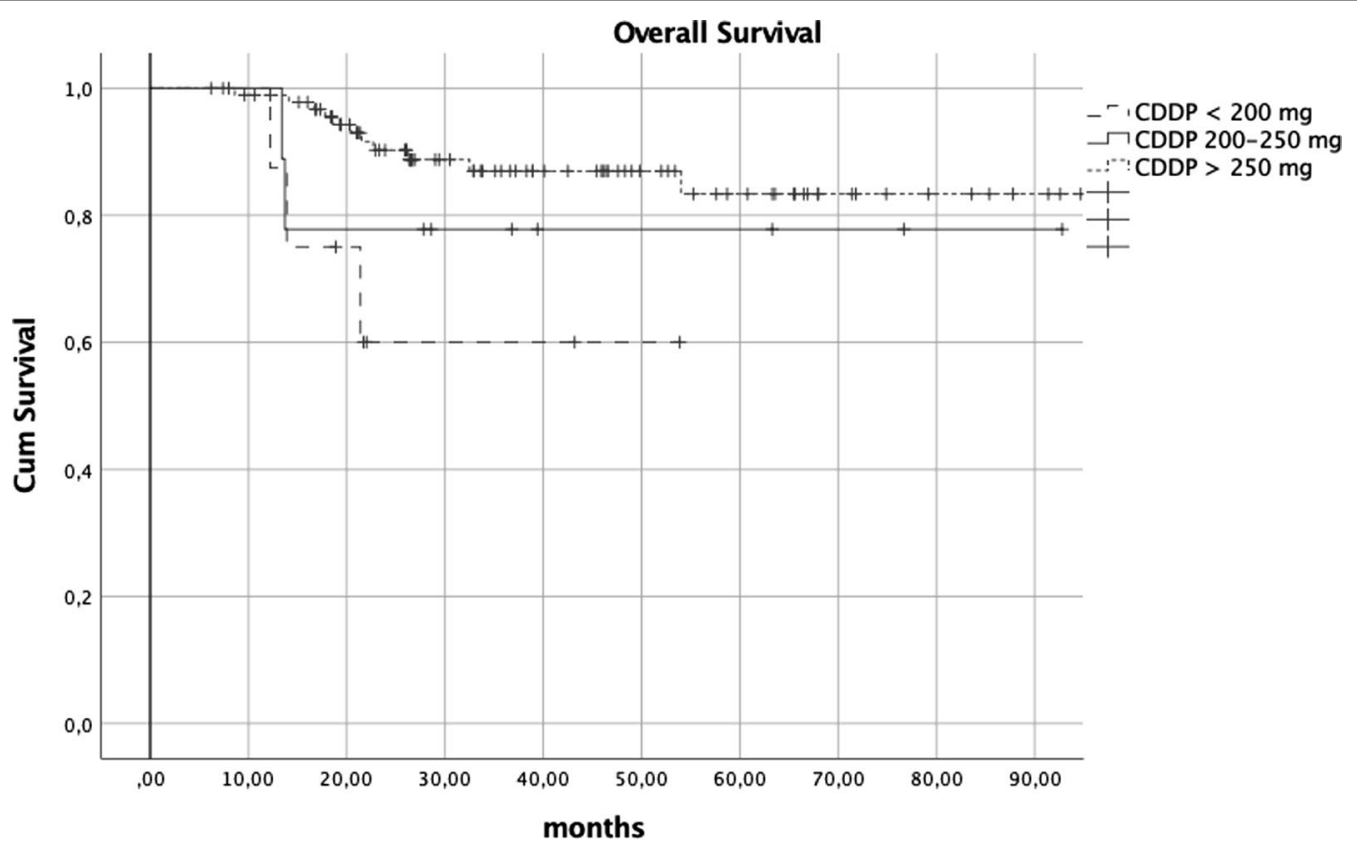

Fig. 2 RFS univariate analysis after PS ( $p=$ not significant)

could thus be related to this important clinical aspect. In terms of acute toxicity, the two groups showed the same hematological toxicity (leukopenia, anemia, thrombocytopenia); less frequent severe intestinal toxicities (nausea and vomiting) were registered in the $1 \mathrm{w}$-CDDP group $(p=0.006)$, whereas severe mucosal toxicity and CDDP delay/interruption were more common in patients with non-nasopharyngeal cancer in the 1-CDDP group $(p<0.0001)$. As far as treatment compliance is concerned, the data are very heterogeneous, since a significant proportion of patients ( $42 \%$ in the weekly CDDP group vs $30 \%$ in the three-weekly group) received neo-adjuvant chemotherapy, possibly reducing the tolerance to the concomitant phase. Another limitation of this study is the cumulative analysis of very different disease sites (including nasopharynx) and of different w-CDDP doses (range, $25-40 \mathrm{mg} / \mathrm{m}^{2} / \mathrm{w}$ ).

Carlsson et al. [23] al retrieved from literature review 13 studies (prospective and retrospective, published between 2014 and 2016) on definitive chemoradiation with single-agent CDDP administered with three different schedules ( $3 w, 1 w /$ daily). Estimated 3-years OS was $68 \%$ and $61 \%$ for $3 w$ versus $1 \mathrm{w} /$ daily regimens, respectively. Similar results were obtained by Jacinto et al. who analyzed seven studies including both primary and adjuvant treatments. No differences were found in terms of 1-year OS. Moreover, data pooled form six of the selected studies showed similar results between the two arms for clinical outcome (5-year PFS) and toxicity profile (renal events, mucositis, dermatitis, treatment interruption and number of patients receiving at least $200 \mathrm{mg} /$ $\mathrm{m}^{2}$ CDDP). Szturz et al. [7] performed a more extensive analysis (52 studies), comparing adjuvant/radical $1 \mathrm{w}-\mathrm{CDDP}$ and $3 \mathrm{w}$-CDDP concomitant to radiotherapy. Results did not show a statistically significant difference in OS and relapse rate between the two treatments. Three-weekly administration, however, appeared to be linked with more severe myelosuppression (leukopenia, $p=0.0083$ and thrombocytopenia, $p=0.0024)$, gastrointestinal toxicity $(p<0.001)$ and severe nephrotoxicity $(p=0.0099)$, while there were no significant differences in mucosal toxicity. Three-weekly administration was also related to inferior compliance: only $71 \%$ of patients completed the full chemotherapy treatment as compared to $88 \%$ of the patients who had w-CDDP. It is also worth noting the different distribution of the disease sites in the two groups, with a higher prevalence of oropharynx cancer in the group undergoing three-weekly chemotherapy (49\% vs $36 \%$ ). A more recent meta-analysis focused on the comparison between 3-w and 1w CDDP, including 
only randomized controlled trial [12]. Results based on 6 studies again confirmed that low dose 1-w CDDP was not associated neither with improved oncologic outcomes nor with lower acute toxicity. Heterogeneity data among the analyzed clinical trials (in terms of both chemotherapy regimens and radiation therapy techniques) as well as the lack of long-term toxicity data represented the main weaknesses of the study.

Recently, along with the reported meta-analyses, phase III randomized trials also have been published. Noronha et al. [6] designed a non-inferiority study, investigating the outcome of patients with LA head-neck carcinoma (except nasopharynx) treated with $30 \mathrm{mg} / \mathrm{m}^{2} \mathrm{w}$-CDDP compared to the $3 \mathrm{w}-\mathrm{CDDP} 100 \mathrm{mg} / \mathrm{m}^{2}$ in postoperative/radical setting. The main endpoint of the study was loco-regional control; the secondary ones included toxicity, compliance and OS. The study included 300 patients (150/arm) but $93 \%$ were in a postoperative setting $(87.3 \%$ oral cavity tumors). The 2-year loco-regional control was significantly higher for the $3 \mathrm{w}-\mathrm{CDDP}(p=0.014)$. The results were confirmed after the comparison of patients receiving total CDDP dose $>200 \mathrm{mg} / \mathrm{m}^{2}$. As for Progression Free Survival (PFS) and OS, however, no statistically significant differences were registered. Regarding toxicity, the $3 \mathrm{w}$ regimen was burdened by more frequent severe acute toxicity $(p=0.006)$ and the hospitalization rate was greater $(p<0.001)$. The main limitation of this study is the small rate of patients treated with radiotherapy alone, due to the preponderance of oral cavity tumors, and the low dose of Cisplatin administered in the weekly schedule $\left(30 \mathrm{mg} / \mathrm{m}^{2}\right)$, compared to the standard of $40 \mathrm{mg} / \mathrm{m}^{2}$. Results of a recent randomized trial performed on 77 patients (39 weekly and 38 3-W CDDP) head and neck cancer patients focused on chemotherapy-related toxicity have been presented by Ameri et al. [8]. Low dose CDDP was administered at $40 \mathrm{mg} / \mathrm{m}^{2}$ and renal indices were considered along with hematologic toxicity. The average estimated glomerular filtration rate (eGFR) resulted to be significantly higher in the $3 \mathrm{w}$ cohort. Moreover, treatment interruption resulted to be primarily due to neutropenia in the $3 \mathrm{w}$ group while renal failure and thrombocytopenia were more frequent among patients treated with the weekly schedule.

Considering the patient reported outcomes, Arbab et al. [9] performed a retrospective analysis on 99 patients (73 patients treated with a $1 \mathrm{w}$ schedule and 26 with a $3 w$ ). Results showed that patients reported outcome resulted to be comparable among the two cohorts of patients.

There have also been several attempts to substitute chemotherapy with cetuximab in old and bad general conditions patients, although the Bonner's Study wasn't designed for such patients $[24,25]$. The results of these studies are not uniform, but the data of the De-Escalate and RTOG 1016 prospective trials [26, 27] as well as those of a smaller Italian trial $[28,29]$ with an emphasis on toxicity, did not confirm the hypothesis of the better compliance and equal efficacy of bio-radiotherapy, particularly in patients with better prognosis (HPV positive disease).

In this context, our study aims to contribute to the body of literature on this controversial issue with a retrospective evaluation of the efficacy and tolerability of the two chemotherapy schedules (1w-CDDP $40 \mathrm{mg} / \mathrm{m}^{2}$ and $3 \mathrm{w}$-CDDP $100 \mathrm{mg} / \mathrm{m}^{2}$ ) administered concurrently with radiotherapy in patients with LA head-neck cancer (oropharynx, hypopharynx and larynx).

The two treatment groups, in our series, are significantly different in relation to patient clinical characteristics (per arm number of patients, gender, age, performance status, alcohol, and smoking habits); higher rates of women, young patients and subjects with better KPS and less smoking and alcohol consumption were registered in the $3 \mathrm{w}$-CDDP group. Moreover, in the same group there was a prevalence of oropharynx cancer, even if they had more advanced nodal disease. Nevertheless, the propensity score method applied for the statistical analysis was able to mitigate these inhomogeneities thus rendering more reliable and robust the presented results.

A non-significantly higher rate of G3-4 hematologic toxicity was observed for the 3-weekly schedule. No significant differences were evident in terms of mucositis or dysphagia. A higher rate of G1-2 thrombocytopenia, mild gastrointestinal toxicity and CDDP interruptions were observed in patients treated with w-CDDP. The higher rate of toxicities could be attributed to the different characteristics of patients treated: more patients with low KPS, older than 70 years and smoke and alcohol addiction were treated with w-CDDP. The subgroup analysis showed that also within subgroup with KPS $\geq 90$ patients of the $1 \mathrm{w}$-CDDP group, are more frequently alcohol and smoking user.

The OS analysis of the present series, not corrected for age, performance status and disease stage, showed a statistically significant better survival for patients treated with $3 \mathrm{w}-\mathrm{CDDP}$ compared to $\mathrm{w}-\mathrm{CDDP}$, with 2 - and 5 -years rates of $95.4 \%$ versus $84.6 \%$ and $95.4 \%$ versus $75.9 \%$, respectively $(p=0.026)$. This result is, probably, related with a selection bias of the patients in the $3 \mathrm{w}$-CDDP group (younger age, better performance status, less smoking and alcohol consumption, and higher rate of HPV positivity). This interpretation of the data is confirmed by the similar survival results registered in the two treatment groups with the propensity scored matched analysis.

The same results have been obtained also for RFS. Similar results (no differences in terms of 5-year OS and 
cancer-specific survival) were obtained by Han et al. [13] in a matched pair analysis on 472 pts (283 treated with 3-w CDDP and 189 treated with $30-50 \mathrm{mg} / \mathrm{m}^{2}$ once weekly). Attention should be posed to give the higher CDDP dose, both with $1 \mathrm{w}$ - or $3 \mathrm{w}$ schedule, for patients with oropharyngeal disease. Moreover, results from the current multivariate analysis after the propensity scored matched analysis on both for OS and RFS showed that neither the interruption of chemotherapy nor the CDDP total dose $/ \mathrm{m}^{2}$ can be identified as an independent prognostic factor.

Propensity score analysis is useful to decrease the biases related to the analysis of a non-randomized population, that however cannot be completely eliminated.

\section{Conclusions}

Three-weekly CDDP still represents the gold standard in curative and postoperative concurrent chemoradiation for LAHNSCC patients, despite the definition of the gold standard of the chemotherapy schedule is still much debated.

This is a retrospective-propensity score matchedanalysis suggesting the two CDDP schedules are not different in terms of survival outcomes. However, these data, since they are retrospective in nature, are not per se sufficient to modify current clinical practice but could confirm, together with other already published data, that $1 \mathrm{w}$-CDDP can be safely used in this group of patients. The lower patients' compliance to the 1w-CDDP schedule could be justified by the worst patients' prognostic factors (older age and lower performance status, alcohol consumption and smoking habits) compared to the $3 w$-CDDP cohort but it should be taken into account when we choose this personalized approach to support the frailty.

\section{Acknowledgements}

IEO the institution of some Authors (DA, MAG, MA, GM, IT, MA, MCR, SMM, BAJF) receives Ricerca Corrente and $5 \times 1000$ research funds from the Italian Ministry of Health. The sponsor did not play any role in study design, execution and data analysis.

\section{Authors' contributions}

All submitting authors have had full access to all data, certify to their integrity and support the decision to submit them for publication.

\section{Funding}

None.

\section{Availability of data and materials}

The datasets analysed during the current study are available from the corresponding author on reasonable request.

\section{Declarations}

Ethics approval and consent to participate

The ethical committee of the two Institutions approved/notified the study.

\section{Consent for publication}

All patients gave written informed consent for the treatment and anonymous use of their data for educational and research purposes.

\section{Competing interests}

Michela Buglione and Daniela Alterio declare conflict of interest with Merck Serono; Stefano M. Magrini declare conflict of interest with Merck Serono, Astellas, Roche, Janssen; Barbara Alicja Jereczek-Fossa declares conflict of interest with Janssen, Ferring, Bayer, Roches, Astellas, Elekta, Carl Zeiss, Ipsen, Accuray, IBA. The other authors have nothing to disclose.

\section{Author details}

${ }^{1}$ Radiation Oncology Department, University and ASST Spedali Civili, Brescia, Italy. ${ }^{2}$ Division of Radiotherapy, Radiation Oncology Department, IEO European Institute of Oncology, IRCCS, Via Ripamonti 435, 20141 Milan, Italy. ${ }^{3}$ Department of Oncology and Hemato-Oncology, University of Milan, Milan, Italy. ${ }^{4}$ Division of Head and Neck Surgery, IEO European Institute of Oncology, IRCCS, Milan, Italy. ${ }^{5}$ Medical Physics, ASST Spedali Civili, Brescia, Italy. ${ }^{6}$ Division of Medical Oncology, IEO European Institute of Oncology, IRCCS, Milan, Italy.

Received: 7 April 2021 Accepted: 7 December 2021

Published online: 20 December 2021

\section{References}

1. Forastiere AA, Goepfert H, Maor M, et al. Concurrent chemotherapy and radiotherapy for organ preservation in advanced laryngeal cancer. N Engl J Med. 2003;349:2091-8.

2. Cooper JS, Pajak TF, Forastiere AA, et al. Postoperative concurrent radiotherapy and chemotherapy for high-risk squamous-cell carcinoma of the head and neck. N Engl J Med. 2004;350:1937-44.

3. Adelstein DJ, Li Y, Adams GL, et al. An Intergroup phase III comparison of standard radiation therapy and two schedules of concurrent chemoradiotherapy in patient with unresectable squamous cell head and neck cancer. J Clin Oncol. 2003;21:92-8.

4. Bernier J, Domenge C, Ozsahin M, et al. Postoperative irradiation with or without concomitant chemotherapy for locally advanced head and neck cancer. N Engl J Med. 2004;350:1945-52.

5. Guan J, Zhang Y, Li Q, et al. A meta-analysis of weekly cisplatin versus three weekly cisplatin chemotherapy plus concurrent radiotherapy (CRT) for advanced head and neck cancer (HNC). Oncotarget. 2016;7(43):70185-93.

6. Noronha V, Joshi A, Patil VM, et al. Once-a week versus once every 3 weeks cisplatin chemoradiation for locally advanced head and neck cancer: a phase III randomized noninferiority trial. J Clin Oncol. 2018;36(11):1064-72.

7. Szturz P, Wouters K, Kiyota N, et al. Low-dose vs. high-dose cisplatin: lessons learned from 59 chemoradiotherapy trials in head and neck cancer. Front Oncol. 2019;21:9-86.

8. Ameri A, Norouzi S, Sourati A et al. Randomized trial on acute toxicities of weekly vs three-weekly cisplatin-based chemoradiation in head and neck cancer. Cancer Rep (Hoboken). 2021; e1425.

9. Arbab M, Chen YH, Criscitiello S, et al. Patient reported outcomes in patients with head and neck cancer treated with concurrent chemoradiation with weekly versus bolus cisplatin. Head Neck. 2020;42(12):3670-7.

10. Pignon JP, le Maître A, Maillard E, et al. Meta-analysis of chemotherapy in Head and Neck Cancer (MACH-NC): an update on 93 randomized trials and 17.346 patients. Radiother Oncol. 2009;92(1):4-14.

11. Szturz P, Wouters K, Kiyota N, et al. Weekly low-dose versus threeweekly high-dose cisplatin for concurrent chemoradiation in locoregionally advanced non-nasopharyngeal head and neck cancer: a systematic review and meta-analysis of aggregate data. Oncologist. 2017:21:1056-66.

12. De Felice F, Belgioia L, Alterio $D$, et al. Survival and toxicity of weekly cisplatin chemoradiotherapy versus three-weekly cisplatin chemoradiotherapy for head and neck cancer: a systematic review and meta-analysis endorsed by the Italian Association of Radiotherapy and Clinical Oncology (AIRO). Crit Rev Oncol Hematol. 2021;162:103345.

13. Han HR, Ma SJ, Hermann GM, et al. Matched pair analysis for comparison of survival outcome of alternative regimens to standard three-weekly 
cisplatin-based concurrent chemoradiation of head and neck cancer. Ann Transl Med. 2021;9(10):913.

14. Edge SB, Compton CC. The American Joint Committee on Cancer: the 7th edition of the AJCC cancer staging manual and the future of TNM. Ann Surg Oncol. 2010;17(6):1471-4.

15. Jiang $L$, Zhang $Y$, Yang Z, et al. A comparison of clinical outcomes between simultaneous integrated boost (SIB) versus sequential boost (SEQ) intensity modulated radiation therapy (IMRT) for head and neck cancer A meta-analysis. Medicine (Baltimore). 2019;98(34):e16942.

16. Bourhis J, Overgaard J, Audry H, et al. Hyperfractionated or accelerated radiotherapy in head and neck cancer: a meta-analysis. Lancet. 2006;368(9538):843-54.

17. Gupta T, Kannan S, Ghosh-Laskar S, Agarwal JP. Concomitant chemoradiotherapy versus altered fractionation radiotherapy in the radiotherapeutic management of locoregionally advanced head and neck squamous cell carcinoma: an adjusted indirect comparison meta-analysis. Head Neck. 2015;37(5):670-6.

18. Homma A, Inamura N, Oridate N, et al. Concomitant weekly cisplatin and radiotherapy for head and neck cancer. Jpn J Clin Oncol. 2011;41(8):980-6.

19. Mohamed A, Twardy B, Zordok MA, et al. Concurrent chemoradiotherapy with weekly versus triweekly cisplatin in locally advanced squamous cell carcinoma of the head and neck: comparative analysis. Head Neck. 2019:41(5):1490-8.

20. Syrigos KN, Karachalios D, Karapanagiotou EM, et al. Head and neck cancer in the elderly: an overview on the treatment modalities. Cancer Treat Rev. 2009;35(3):237-45.

21. Juarez JE, Choi J, St John M, et al. Patterns of care for elderly patients with locally advanced head and neck cancer. Int J Radiat Oncol Biol Phys. 2017;98(4):767-74.

22. Siddiqui F, Gwede CK. Head and neck cancer in the elderly population. Semin Radiat Oncol. 2012;22(4):321-33.

23. Carlsson L, Bratman SV, et al. The cisplatin total dose and concomitant radiation in locoregionally advanced head and neck cancer: any recent evidence for dose efficacy? Curr Treat Options Oncol. 2017;18(7):39.

24. Walsh L, Gillham C, Dunne M, et al. Toxicity of cetuximab versus cisplatin concurrent with radiotherapy in locally advanced head and neck squamous cell cancer (LAHNSCC). Radiother Oncol. 2011;98(1):38-41.

25. Mehanna H, Robinson M, Hartley A, et al. Radiotherapy plus cisplatin or cetuximab in low-risk human papillomavirus-positive oropharyngeal cancer (De-ESCALaTE HPV): an open-label randomised controlled phase 3 trial. Lancet. 2019;393(10166):51-60.

26. Gillison ML, Trotti AM, Harris J, et al. Radiotherapy plus cetuximab or cisplatin in human papillomavirus-positive oropharyngeal cancer (NRG Oncology RTOG 1016): a randomised, multicentre, non-inferiority trial. Lancet. 2019;393(10166):40-50.

27. Koutcher L, Sherman E, Fury M, et al. Concurrent cisplatin and radiation versus cetuximab and radiation for locally advanced head-and-neck cancer. Int J Radiat Oncol Biol Phys. 2011;81(4):915-22.

28. Magrini SM, Buglione M, Corvò R, et al. Cetuximab and radiotherapy versus cisplatin and radiotherapy for locally advanced head and neck cancer: a randomized phase II trial. J Clin Oncol. 2016;34(5):427-35.

29. Buglione M, Maddalo M, Corvò R, et al. Subgroup analysis according to human papillomavirus status and tumor site of a randomized phase II trial comparing cetuximab and cisplatin combined with radiation therapy for locally advanced head and neck cancer. Int J Radiat Oncol Biol Phys. 2017;97(3):462-72.

\section{Publisher's Note}

Springer Nature remains neutral with regard to jurisdictional claims in published maps and institutional affiliations.
Ready to submit your research? Choose BMC and benefit from:

- fast, convenient online submission

- thorough peer review by experienced researchers in your field

- rapid publication on acceptance

- support for research data, including large and complex data types

- gold Open Access which fosters wider collaboration and increased citations

- maximum visibility for your research: over $100 \mathrm{M}$ website views per year

At BMC, research is always in progress.

Learn more biomedcentral.com/submissions 